\title{
Using GIS to Teach Place-Based Mathematics in Rural Classrooms
}

\author{
Jacqueline Leonard \\ University of Wyoming \\ Nicole M. Russell \\ University of Denver \\ Robert M. Hobbs \\ Trenton Central High School, New Jersey \\ Heather Buchanan \\ University of Wyoming
}

The purpose of this article is to promote the use of GIS and place-based education (PBE) in rural mathematics classrooms. The pedagogy of place is disappearing from rural communities because of declining enrollments, lack of support, and federal mandates to focus more on basic academic skills. However, PBE does not stand in opposition to standards-based instruction and academic achievement; rather, it enhances instructional strategies for getting at these aims. We present examples of place that can be used to engage rural students in meaningful mathematics activities to improve their content knowledge and problem-solving ability. Barriers exist to full implementation of this work. Yet, we offer a vision of what is possible through the use of technological tools like GIS for teachers who teach in rural communities. Additional studies regarding the effect of using GIS are needed to bring the vision of situated place-based education closer to fruition.

Key Words: Graphic Information Systems; mathematics education; place-based education; rural schools

Placed-based education (PBE) is experiencing resurgence in U.S. schools as a supplement to traditional instruction (Akom, 2011; Howley, Showalter, Howley, Howley, Klein, \& Johnson, 2011). PBE can be traced to Dewey (1912) who contended that the experience students bring from out-of-school settings (i.e., place) should be incorporated into meaningful classroom activities (Long, 2009). The Center for Place-Based Learning and Community Engagement ${ }^{1}$ purports that PBE "immerses students in local heritage, cultures, landscapes, opportunities, and experiences" that can provide a foundation for learning the core curriculum (i.e., language arts, mathematics, social studies, and science). According to Gruenewald (2003a),

Place matters to educators, students, and citizens in tangible ways that include providing teachers and students with "firsthand experience" to link local contexts

\footnotetext{
${ }^{1}$ Quote from Center for Place-Based Learning and Community Engagement website: http://www.promiseofplace.org/what_is_pbe
}

to learning environments in order to understand sociopolitical processes and shape what happens in the local community. (p. 620)

Place-based education operates under the assumption that education is not place-less but grounded somewhere in order for learning to take place (Aikenhead, Barton Calabrese, \& Chinn, 2006). Place-based learning has roots in the local community - it's culture, economy, history, and the arts; the community serves as the context for learning, and business and community leaders serve as resources (The Rural School and Community Trust as cited in Shamah \& MacTavish, 2009). Thus, place and culture are intertwined such that "to live is to live locally, and to know is first of all to know the places one is in" (Casey, as cited in Gruenewald 2003a). Through place, students learn about how the world functions and how their lives fit into the spaces they occupy, which can reinforce important motivational ideas such as belonging, reclaiming space, and realworld relevance (Gruenewald, 2003a; hooks, 2009).

\section{Purpose}

The purpose of this paper is to explore ways in which rural teachers can promote place-based 
education in mathematics classrooms. Place-based education began in rural settings in the 1980s (Howley et al., 2011) and is a natural fit in terms of providing an authentic context for rural students to learn. While critics of PBE contend that this pedagogy takes a great deal of time and planning (Howley et al., 2011), it can be implemented in the mathematics classroom with the use of Graphic Information Systems (GIS) because it makes place readily accessible.

Rural areas, which tend to suffer from outmigration (i.e., loss of citizens to urban areas) (Holloway, 2002; Howley et al., 2011) could benefit from the use of this technological tool. Teachers can use GIS to engage students in PBE as a means to reduce the undervaluing of place. In this case, authentic learning experiences in mathematics occur as a means to increase appreciation for the uniqueness of the rural community. Thus, teachers can use GIS as an instructional tool to motivate rural students to learn important subject matter within the context of place.

In order to ground our work, we first present a theoretical construct to frame the use of place-based education. Second, we discuss a rationale for using placed-based education in the mathematics classrooms. Third, we provide applications of GIS that teachers can use. Fourth, we discuss barriers and possible solutions to using place-based education. Fifth, we discuss the need for additional studies in place-based mathematics education (PBME) that use strategies like GIS to measure the impact of PBME on student outcomes. Finally, we summarize why it is important to use GIS to promote place-based education in today's classrooms.

\section{Theoretical Framework}

While no single theory of place exists, placebased practices can be connected to experiential learning, outdoor education, indigenous education, environmental and ecological education, bioregional education, multicultural education, and other pedagogical approaches that value specific places, locales, and regions where people live and work (Gruenewald, 2003a \& 2003b). Underlying many of these approaches is the notion that pedagogical experiences should be connected to students' lives in meaningful ways (Gay, 2000). Moreover, PBE can be used to help students develop a critical stance to address environmental issues in their communities, thus creating a more democratic and just society (Banks, 2002). Thus, PBE is related to teaching for social justice because it can be used to empower students to engage in critical reflection that leads to action to change the status quo. Gruenewald (2003a
\& 2003b), who contends PBE is undertheorized, aligned it with critical pedagogy.

Critical pedagogy evolved from critical theory, which was articulated by Paulo Freire (1970/1995) and applied to the field of education (McLaren \& Giroux, 1990; Ladson-Billings, 1998) to "challenge the assumptions, practices, and outcomes taken for granted in dominant culture and in conventional education" (Gruenewald, 2003b, p. 3). Burbules and Berk (1999) define critical pedagogy as:

An effort to work within educational institutions and other media to raise questions about inequalities of power, about the false myths of opportunity and merit for many students, and about the way belief systems become internalized to the point where individuals and groups abandon the very aspiration to question or change their lot in life. (p. 50)

We use critical pedagogy as a construct for this article. However, like other critical pedagogies, many teachers are at a loss regarding how to implement place-based pedagogy in everyday classrooms, especially in mathematics classrooms. In this paper, we provide teachers with rich examples to build a foundation to teach place-based mathematics education.

\section{Why Place-Based Mathematics Education?}

Empirical studies that examine place-based mathematics instruction in U.S. schools are sparse (Howley et al., 2011). While the evidence on the benefits of using PBME is thin, brain-based researchers (Bransford, Brown, \& Cocking, 2000) contend that students' emotions have an impact on learning. Researchers (Bransford et al., 2000) suggest that making connections to the real world positively influences students' emotions, which in turn influences their engagement. Positive mathematics identities and empowerment result from engagement in lessons that are linked to place (Gruenewald, 2003a; Tate, 2008). PBME has the capacity to engage students emotionally and increase student engagement, which potentially then impacts student retention and academic performance.

Mathematics problems specific to rural regions of the U.S. can be used for context. Events such as community festivals in Appalachia can be used in everyday mathematics classrooms. Production of beverages at plants like Mountain Dew in Tennessee, Coca-Cola in Georgia, and Pepsi in Wyoming may be collected and compared in terms of market share, production costs, and profit margins. Students could also debate the nutritional value versus the caloric consumption of such products in terms of costbenefit. Mineral and water rights as well as other 
issues of environmental and ecological concern can also serve as the context for learning and doing mathematics in rural spaces. Not only are such activities connected to the real world, but they are also connected the neighborhoods and communities where students live. Thus, students have the opportunity to learn rigorous mathematics content knowledge within a place-based context while simultaneously learning about issues of importance to the economy, health, and wellbeing of rural citizens.

\section{Graphic Information Systems Applications}

PBME can further facilitate enjoyment and learning if it is connected to technologies like Graphic Information Systems (GIS). GIS is defined as "an interactive mapping and analysis tool [that] allows multiple layers of information about a given place to be represented simultaneously, thus exposing the interactions among layers and... [the] conception of neighborhood to be represented in greater complexity" (Talen \& Shah 2007, p. 583). GIS has been used in classrooms for more than 30 years, becoming part of geography courses in higher education as early as the 1980s (Elwood, 2009). Teachers can use web-based programs like Google Earth and Google Maps to engage students in spatial technologies and PBE (Hogrebe \& Tate, 2012; Leonard, Brooks, Barnes-Johnson, \& Berry, 2010). While GIS projects have been shown to inform urban communities about civic planning and action, (Elwood, 2009; Talen \& Shah, 2007), few have used GIS to empower rural communities. GIS projects not only provide opportunities that focus "on place and space as important contextual variables" (Hogrebe \& Tate, 2012), they can also be used to evaluate the boundaries of farms, parks, residential and commercial areas, activity patterns, and community preferences regardless of locale (Talen \& Shah, 2007).

Changing teachers' and students' views of mathematics as a set of disconnected rules and facts to be memorized and regurgitated is a continuous challenge. GIS can be used to change attitudes by helping teachers and students to better understand their world (i.e., place-based education). Teachers of rural students can use GIS to engage their students in meaningful mathematics problems and investigations that value issues and resources specific to their communities (Brantlinger, 2005; Gruenewald, 2003a; Hogrebe \& Tate, 2012; Tate, 2008). For example, Brantlinger (2005) used a map of his students' community to help them discover its assets (e.g., parks and recreation centers). Students learned concepts such as radius, circumference, and diameter as they examined the assets that were within a 3-mile radius of their neighborhood. Google Maps can be used in rural classrooms to accomplish the same academic goals.

We discuss two examples used by classroom teachers in small towns and then provide several other examples that can be used by teachers in small towns and rural areas throughout the U.S. The first example is the use of a Google Maps project in New Jersey. The second example uses GIS to locate a pumpkin farm in western Wyoming.

\section{The Google Maps Project}

In Trenton, New Jersey, a high school mathematics teacher explained how he used GIS to help his students learn how to find and calculate slope. His reflections and the essence of his lesson plan are presented below:

The Google Maps Classroom Project actually began when I introduced ninth-grade Algebra I students to a lesson on how to find the slope of a line given two sets of points. After students were familiar with this concept, they were prepared to put what they had learned into practice.

Each student was given a sheet of graph paper and asked to superimpose an $x$ - and y-axis through the center and label the origin. We then proceeded to the lab where all students were instructed to go to Google Maps and locate our school. The school was the origin for the map. Students then located their homes on the map and were asked to place the origin (center) of the graph paper directly on the computer monitor where the school was to make sure that the $x$ and y-axes were properly lined up. Students were asked to place a point on their homes and labeled that point with the letter $H$. After the students labeled the point where their homes were, I instructed them to place the scale (from Google Maps) that was associated with the distance between their home and the school at the bottom of their graph sheets (1inch $=2,000$ ft., 1 inch $=1,000 \mathrm{ft}$., etc.). I informed them that the scale at the bottom of their papers would be the same scale that they would use when locating other places on their maps.

I then asked students to locate the nearest CVS and Rite-Aid pharmacies, Save-A-Lot and ShopRite grocery stores, the closest corner stores and farmer's market. I instructed students that each time they located an object on the graph to use the school as their origin and to make sure the graph paper was always facing north or in the positive $y$ direction. In addition to this, the scales that they used had to always match up with the scales at the bottom of their graph paper before 
they actually labeled them. Finding directions to different places that have different distances from the origin often result in the scales changing. For this project to work successfully, students had to establish a common scale.

A week or so later the students were asked to mark the intervals on their graphs based on the scales at the bottom of their papers. When this was completed the students began to assign coordinates to the points they labeled the week before. Ultimately, students found the slope of the line between the school, their homes, and several other points. Students determined the slope of these lines by using the coordinates of the two points [slope $\left.=\left(y_{2}-y_{1}\right) /\left(x_{2}-x_{1}\right)\right]$ or by simply counting the grid lines [ slope $=($ rise $)$ / $($ run $)=($ change in $y) /($ change in $x)]$ (see Figure 1 below).

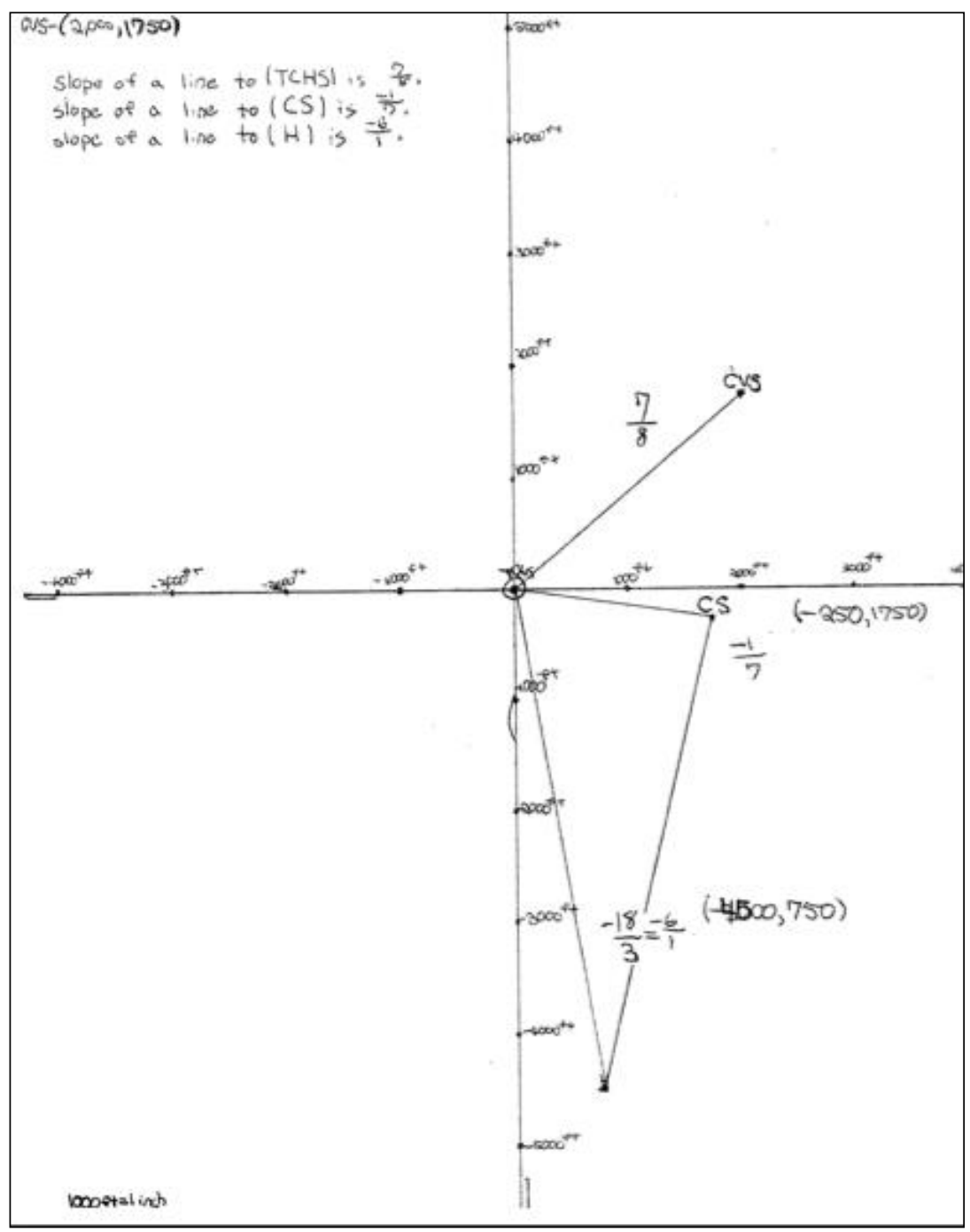

Figure 1. Student work sample

The Google Maps project reveals how students experienced a great deal of success solving complex math problems by relating the problem to the place. Learning the concept of slope is not trivial. One of the more difficult questions on the National Assessment of Education Progress (NAEP, 2011) was as follows: Which of the following is an equation of a line that passes through the point $(0,5)$ and has a negative slope? In the Google Maps Project example, students had to calculate both positive and negative slopes. Positive slopes tilt toward the right on a map, and negative slopes tilt toward the left. Students are more likely to remember these subtleties when they are anchored to their own neighborhoods. 
After finding the slope, students can easily write an equation for the line by using the point-slope formula: $y=m x+b$.

\section{GIS and the Pumpkin Patch}

In addition to using GIS to find distances and slopes, the terrain feature can be used to identify how land is being used. For example, in Wyoming there are many open spaces and mountain ranges.

However, farms can be easily identified in an aerial view using Google Maps. A second teacher in a rural town described how her students used placed-based mathematics education:

I have personally experienced how most students were motivated to learn more about their world and the excitement that teachers have when they see their students learning on a whole new level. Spending a long week with students near Jackson Hole, Wyoming, they physically experienced various landscapes, weather, wildlife, and vegetation. They learned leadership skills, how to read a map, and survive in their land. Students also gathered random samples on a second trip to a local pumpkin farm in Riverton, Wyoming, and used the data to analyze the pumpkin's weight, circumference, density, and volume. All of the students used Excel to calculate measures of central tendency, random sampling, correlation, and finding an equation for the "line of best fit". This activity was a challenge for my lower skilled math students, but relatively simple for the upper grades (Algebra II \& Geometry). I had to keep the activity simple because of the small number [of students] in the school, time constraints, and [personal limitations] to help those students with lower math skills. Typically, our more advanced students became more involved while I had to encourage our lower skilled students to "do their own work."

While the experiences the students had were positive, this teacher's reflection brings up the issue of small group learning. Individual student work, which is typically found in traditional mathematics classroom settings, should not apply in PBME. Students should be able to learn procedural knowledge from each other in small groups, allowing stronger students to help weaker ones (Leonard, 2001). In this way, all students benefit because stronger students learn to articulate their thoughts to others as a peer coach and weaker students benefit from one-on-one instruction. The teacher could then spend more time working with groups who need her help.
Furthermore, this teacher's experience conflicts with the findings of Howley et al. (2011) that teachers of more advanced students are less likely to engage them in PBME. Howley et al. (2011) found that students in vocational education tracks are more likely to experience PBME in the mathematics classroom. Given the wide range of abilities in this teacher's classroom, her experience reveals that students of all achievement levels can benefit from PBME. Albeit, thoughtful organization of small groups during all aspects of the activities, including procedural knowledge, would appear to enhance lowachieving students' opportunities to learn.

\section{Additional Opportunities for PBME in Wyoming}

Many more examples of place can be used to engage rural students in meaningful mathematics activities to improve their mathematics content knowledge and problem-solving ability. Here we provide a few examples of such opportunities for rural students in Wyoming.

GIS and Saratoga. The landscape and resources of the Saratoga area in Wyoming provide an interesting example of place. The natural hot springs of Saratoga are a popular tourist attraction. Connecting mathematics to place, students could use the high school in Saratoga as the point or origin to determine the distance from the school to the springs and the slope line from the school to the springs or the airfield.

In addition to calculating the distances, slopes, and the equations of the lines, the grounds of the Saratoga Resort have smaller springs that are covered by tipis (See Figure 2). Students could estimate the amount of material needed to make one of the tipis as well as determine the surface area of a tipi using the formula to find the surface area of a cone.

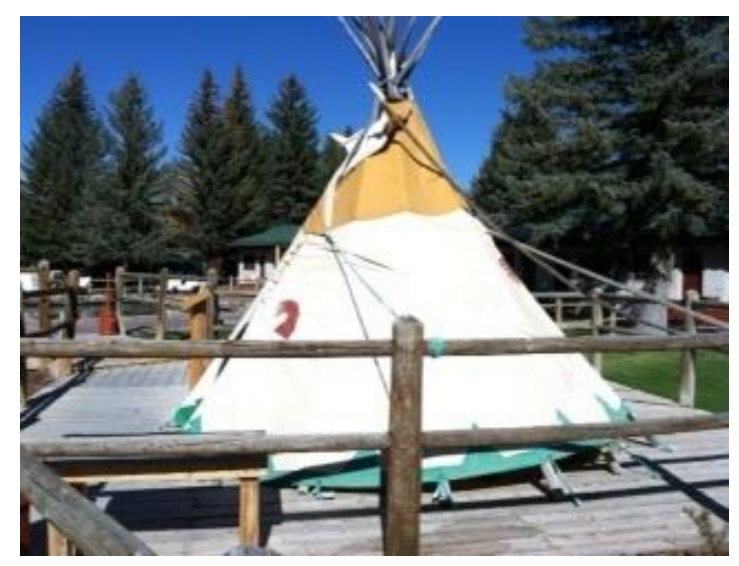

Figure 2. Tipi at Saratoga Resort 
Frontier Days. Another place-based activity that provides context for rural students is Frontier Days, which takes place annually in Cheyenne, Wyoming, during the month of July. People from all over the United States travel to see the rodeo and participate in the festivities. Frontier Days provides students with the opportunity to make predictions related to probability, for example: How long can a cowboy ride a Bronco. Problems that deal with purchasing western wear and consuming food could also be created. Projections and calculations of revenue for a given year and for future years could also serve as mathematics investigations.

The Snowy Range. The Snowy Range is also a place with which students in Wyoming can identify. Skiing lessons can be taken and lift tickets purchased. A myriad of mathematical problems could be developed around the ski season and this sport. Even though students may not be able to afford to go skiing, they can identify with snow and snowboarding activities. Word problems that incorporate weather in terms of snowfall, average temperature, and wind speed can also be used to engage in rigorous mathematics. Students can record data and graph stem-and-leaf plots based on the data.

State resources. Wyoming resources can also be used as a context for engaging in place-based mathematics. The railroad is a viable part of the Wyoming economy. Moreover, Wyoming is the primary producer of coal in the United States, supplying coal to more than 27 states and more than 130 power plants nationwide. About $80 \%$ of the cost of coal is associated with its transportation. Algebra problems involving the movement of trains carrying coal in and out of Wyoming could be used as the context to explore linear equations. Rather than solving an arbitrary problem of two trains traveling at different speeds to determine when they meet, the coal trains could be used for context. Mathematics problems exploring the number of tons of coal needed to produce electricity for communities in Wyoming could also be incorporated.

\section{Overcoming Barriers to Place-Based Education}

The places where children reside create both opportunities and challenges when it comes to learning outcomes and educational attainment (Aikenhead et al., 2006; Leonard, Napp, \& Adeleke, 2009; Morris \& Monroe, 2009; Tate, 2008). Challenges include the fact that PBE is disappearing from rural communities because of declining enrollments, lack of support, and federal mandates for accountability that have led to a greater focus on basic academic skills in many rural schools (Howley et al., 2011; Shamah \& MacTavish, 2009). While little can be done about declining enrollments, per se, teachers can address outmigration by using place to highlight the cultural capital of the local community. One way that cultural capital can be understood is through exploring the resources within a community that can be used and appropriated for economic development or educational ends (Beadie, 2008). The Wyoming Rural Development Council (WRDC) is an example of how rural communities are engaging in the ideas of community partnership. Their mission is to enhance collaborations that strengthen the viability of rural Wyoming. An important goal of this organization is to promote (through education) an understanding of the needs, values, and most importantly the contributions of rural communities. Thus, teachers have a rich opportunity to address outmigration and emphasize the cultural capital of the local communities in which students live.

Lack of support can be addressed in two ways. First, principals and other administrators must buy in and support teachers' efforts to teach from a placebased perspective (Gruenewald, 2003a; Howley et al., 2011). In addition, principals should support teachers rather that penalize them for diverging from the traditional curriculum. Moreover, schools may not have funding for extensive professional development on best practices in terms of using PBME. Thus, articles like this one provide teachers with an important resource. Another way to support teachers' work in place-based education is with materials and supplies. While many school districts are still feeling the crunch of the 2008 economic downturn, grants are available to supply teachers with materials and supplies to conduct projects with their students through organizations like the National Council of Teachers of Mathematics and the Junior League (Leonard, 2004).

In terms of accountability, GIS and place-based mathematics education (PBME) can be used to teach important mathematics content and to engage rural students at higher levels. PBE does not stand in opposition to standards-based instruction and academic achievement. Rather than replacing the traditional curriculum, PBME can be used to supplement it, introducing the mathematics concepts and helping students to recognize and use mathematics for a purpose (Long, 2009). This technique of introducing the lesson with PBME can be used in both elementary and secondary classrooms with students of various achievement backgrounds without sacrificing mathematics content. 


\section{Need for Research}

While several of the examples provided in this article have not been field-tested or observed in rural $\mathrm{K}-12$ classrooms, we believe students in rural schools would be motivated to engage in problems that deal with familiar places rather than focus only on textbook problems. However, studies of PBME in rural spaces are needed to validate our assumptions. Clearly, there is a need for additional studies that examine PBME.

We know that GIS is a valuable way to teach mathematics concepts and skills, particularly many of the skills emphasized by NCTM (2000) like representing numbers visually, understanding patterns and relationships, and using geometric and spatial relationships. However, there is still a lot to learn and understand about how using this tool influences students' performance on accountability measures at state and national levels. PBME may not be appropriate to teach every mathematics topic. However, brain-based research is expanding, particularly in science and mathematics (Bransford et al., 2000). Conducting brain-based research to determine which PBME activities students find more enjoyable would be a tremendous scientific breakthrough. Additional studies are needed to show how students' emotions are effected by critical pedagogies like PBME. Such studies may provide evidence to support PMBE as a best practice in rural contexts.

\section{Summary}

In an era of high accountability, K-12 teachers in U.S. schools are often conflicted when it comes to making decisions about how to teach mathematics. However, we have shown that GIS is readily accessible and just a click or two away. All students need to do is click on Google Maps, insert the school address, then click on find nearby and enter the name of a business or community asset on the computer. Use of GIS in the mathematics classroom provides rural students with authentic learning opportunities that bring the vision of situated place-based education and quality mathematics instruction for all students closer to fruition. The array of mathematics that can be done using GIS and place-based learning is numerous. From algebra (determining slopes and linear equations), to geometry (finding radius, perimeter, area), and from data analysis (graphs and interpretation of data) to locating a pumpkin farm, the range of mathematics activities is only limited by teachers' and students' imaginations.

Teachers have very little control over federal and state policies when it comes to accountability. In the era of No Child Left Behind (2001), teachers and schools are under tremendous pressure to show higher gains on standardized tests. However, if student achievement in a particular school has plateaued (i.e., reached ceiling effect), something different has to be done to bring about change. Placebased education may be the change that can motivate students of all achievement levels to engage and succeed in mathematics. Administrators and teachers must be willing to take risks in order to increase achievement, especially in rural schools where focusing solely on basic skills has not produced the desired results.

\section{References}

Aikenhead, G., Barton Calabrese, A., \& Chinn, P. W. U. (2006). Forum: Toward a politics of placebased science education. Cultural Studies of Science Education, 1, 403-416.

Akom, A. (2011). Eco-apartheid: Linking environmental health to educational outcomes. Teachers College Record, 113(4), 831-859.

Banks, J. A. (2002). Race, Knowledge Construction, and Education in the USA: Lessons from history. Race Ethnicity and Education, 5(1), 7-27.

Beadie, N. (2008). Education and the creation of capital: Or what I have learning from following the money. History of Education Quarterly, $48(1), 1-29$.
Bransford, J. D., Brown, A. L., \& Cocking, R. R. (2000). How people learn: Brain, mind, experience, and school. Washington, DC: National Academy of Sciences.

Brantlinger, A. (2005). The geometry of inequality. In E. Gutstein, \& B. Peterson (Eds.), Rethinking mathematics: Teaching social justice by the numbers (pp. 97 - 100). Milwaukee, WI: Rethinking Schools.

Burbules, N. \& Berk, R. (1999). Critical thinking and critical pedagogy: Relations, differences, and limits. In T. Popkewitz \& L. Fendler (Eds.), Critical theories in education. New York: Routledge. 
Dewey, J. (1916). Democracy and education: An introduction to the philosophy of education. New York: Macmillan.

Elwood, S. (2009). Integrating participatory action research and GIS education: Negotiating methodologies, politics and technologies. Journal of Geography in Higher Education, 33(1), 51-65.

Freire, P. (1995). Pedagogy of the oppressed. New York: Continuum. (Original work published 1970).

Gay, G. (2000). Culturally responsive teaching: Theory, practice, and research. New York: Teachers College Press.

Gruenewald, D. A. (2003a). Foundations of place: A multidisciplinary framework for place-conscious education. American Educational Research Journal, 40(3), 619-654.

Gruenewald, D. A. (2003b). The best of both worlds: A critical pedagogy of place. Educational Researcher, 32(4), 3-12.

Hogrebe, M. C. \& Tate, W. F. (2012). Geospatial perspective: Toward a visual political literacy project in education, health, and human services. Review of Research in Education, 36, 67-94.

Holloway, D. L. (2002). Using research to ensure quality teaching in rural schools. Journal of Research in Rural Education, 17(1), 138-153.

hooks, b. (2009). Belonging: A culture of place. New York: Routledge.

Howley, A., Showalter, D., Howley, M. D., Howley, C. B., Klein, R., \& Johnson, J. (2011). Challenges for place-based mathematics pedagogy in rural schools and communities in the United States. Children, Youth and Environments, 21(1), 101-127.

Ladson-Billings, G. (1998). Just what is critical race theory and what's it doing in a nice field like education? International Journal of Qualitative Studies in Education, 11(1), 7-24.

Leonard, J. (2001). How group composition influenced the achievement of sixth-grade mathematics students. Mathematical Thinking and Learning, 3(2\&3), 175-199.
Leonard, J. (2004). A tale of two cities: Integrating language arts, mathematics, and social studies. Middle School Journal, 35(3), 35-40.

Leonard, J., Brooks, W., Barnes-Johnson, J., Berry, R. Q., III. (2010). The nuances and complexities of teaching mathematics for cultural relevance and social justice. Journal of Teacher Education, 61(3), 261-270.

Leonard, J., Napp, C., \& Adeleke, S. (2009). The complexities of culturally relevant pedagogy: A case study of two mathematics teachers and their ESOL students. High School Journal, 93(1), 322.

Long, V. M. (2009, September/October). Adding "place" value to your mathematics instruction. Connect Magazine, 10-12.

McLaren, P., \& Giroux, H. (1990). Critical pedagogy and rural education: A challenge from Poland. Peabody Journal of Education, 67(4), 154-165.

Morris, J. E., \& Monroe, C. R. (2009). Why study the U.S. South" The nexus of race and place in investigating Black student achievement. Educational Researchers, 38(1), 21-36.

National Council of Teachers of Mathematics. (2000). Principles and Standards for School Mathematics. Reston, VA: The Council.

National Assessment of Educational Progress. (2011). The nation's report card. Retrieved from http://nationsreportcard.gov/math_2011/gr8_nati onal.asp

No Child Left Behind: Reauthorization of the Elementary and Secondary Education Act of 2001. (2001). A report to the nation and the Secretary of Education, U.S. Department of Education, President Bush Initiative.

Shamah, D., \& MacTavish, K. A. (2009). Making room for place-based knowledge in rural classroom. The Rural Educator, 30(2), 1-4.

Talen, E., \& Shah, S. (2007). Neighborhood evaluation using GIS: An exploratory study. Environment and Behavior, 39, 583-615.

Tate, W. F. (2008). "Geography of opportunity”: Poverty, place, and educational outcomes. Educational Researcher, 37(7), 397-411.

\section{About the authors:}

Jacqueline Leonard is the Director of the Mathematics and Science Teaching Center at the University of Wyoming.

Nicole M. Russell is an assistant professor of teacher education at the University of Denver.

Robert Hobbs in a mathematics teacher at Trenton Central High School in Trenton, New Jersey.

Heather Buchanan is a former teacher and student in the Middle Level Mathematics Masters' Degree program at the University of Wyoming. 